\title{
Experimental Measurement of Oil Film Temperatures of Elliptical Journal Bearing Profile Using Different Grade Oils
}

\author{
Rakesh Sehgal \\ Department of Mechanical Engineering, NIT \\ Hamirpur-177005 (H. P.), India \\ E-mail: rsehgal@nitham.ac.in
}

( Manuscript received 29 September 2010; accepted 10 November 2010; published 30 November 2010 )

\begin{abstract}
A significant variation in oil film temperature has been observed in hydrodynamic journal bearings. Here, a journal bearing test rig has been developed to measure the oil film temperature on the three circumferential planes of the journal bearing. Further, an elliptical journal bearing with $D_{\text {Imin }}=65.2 \mathrm{~mm}, O D=85 \mathrm{~mm}$ and $L=$ $65 \mathrm{~mm}, C_{m}=200 \mu \mathrm{m}$ and $C=300 \mu \mathrm{m}$ has been designed and tested to access the temperature rise at oil bush interface with three grade oils namely Oil 1, Oil 2, and Oil 3 at loads $=200 \mathrm{~N}, 400 \mathrm{~N}$, and $500 \mathrm{~N}$ and speeds $=$ $3000,3500,4000 \mathrm{rpm}$ at constant oil supply pressure. The results show that with increase in the load at constant speed and pressure, and with increase in speed at constant load and pressure, the oil film temperature increases in the central plane of both the lobes of the bearing for all the grade oils. The nature of the oil film temperature distribution along the circumference of the journal bearing has been observed very close to the oil film temperature distribution reported in the literature.
\end{abstract}

Keywords: elliptical journal bearing, oil film temperature, journal bearing test rig

\section{Introduction}

Bearing performance is significantly affected by thermal changes as lubricant viscosity is a strong function of temperature. Excessive rise in temperature can cause oxidation of the lubricant and, consequently, lead to failure of the bearing. Researchers have tried to study the behaviour of the lubricant film by adopting various approaches of simulation in accordance with the real conditions. Literature reveals that the temperature rise is quite high in circular bearings as they operate with a single active oil film. This has encouraged the researchers in the development of bearings with non-circular profiles. These bearings have a common feature that they operate with more than one active oil film. This feature accounts for the superior stiffness, improved damping, low power losses and reduced temperature in oil film as compared to the circular journal bearings.

Out of non-circular journal bearings, elliptical, offset-halves, and three-lobe configurations are the most common. Among these non-circular bearings the elliptical journal bearings are commonly used in turbo-sets of small and medium ratings. The so-called elliptical journal bearing is actually not elliptic in crosssection but is usually made up of two circular arcs whose centers are displaced along a common vertical straight line from the centre of the bearing, as shown in Fig. 1. Limited experimental work has been reported for the thermal effects in lobed bearing configurations such as offset-halves and elliptical/lemon bore journal bearings. Moreover, no standard procedures for the design of such non-circular bearings are available as on today.

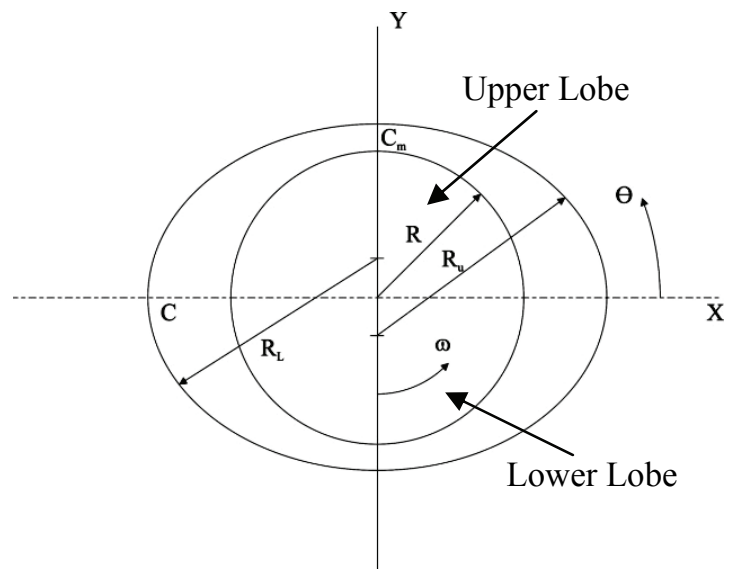

Fig. 1 Schematic diagram of elliptical journal bearing

To maintain brevity only few recent experimental and theoretical works are reviewed here. Pinkus and Lynn ${ }^{1)}$ 
have presented an analysis of elliptical journal bearings based on the numerical solution of Reynolds equation for finite bearings with the assumption that there is no heat loss to the surroundings. The solution of the differential equation was supplemented by additional work on the nature of the oil flow, power loss, and eccentricity in elliptical bearings. An attempt was made by Suganami and $\mathrm{Sezri}^{2)}$ to formulate a thermohydrodynamic model of film lubrication which is valid in both laminar and superlaminar flow regimes. The authors stated that the energy equation retains heat conduction in the direction of sliding motion, and is applicable even at large eccentricities. Crosby ${ }^{3)}$ solved full journal bearing of finite length for thermohydrodynamic case in which the energy transmitted by conduction is included. The effect of temperature variation across the film thickness on bearing performance is investigated by the author.

Singh and Gupta ${ }^{4)}$ considered the stability limits of elliptical journal bearings supporting flexible rotors. The Reynolds equation was solved numerically for several values of the eccentricity ratio, the $L / D$ ratio and the dimensionless velocity of the journal centre by the authors. The authors observed that the operating load, ellipticity, $L / D$ ratio and shaft flexibility significantly affect the limit of stable operation and reported that elliptical bearings are suitable for stiff and moderately flexible rotors. Tayal et al. ${ }^{5)}$ investigated the effect of additive-fortified lubricants (behave as non Newtonian fluids) non-linear behavior on the performance characteristics of the finite width elliptical hydrodynamic journal bearing using cubic shear stress law. The finite element method with Galerkin's technique was used by the authors, to solve the Navier-Stokes equations (in cylindrical co-ordinates) that represents the flow field in the clearance space of a bearing using Newtonian fluids, and then the non-Newtonian effect was introduced by modifying the viscosity term for the model in each iterations.

Boncompain et al. ${ }^{6}$ presented a general thermohydrodynamic theory. The authors have solved the generalized Reynolds equation, the energy equation in the film and heat transfer equation in the bush and shaft simultaneously. Read and Flack ${ }^{7)}$ developed a test apparatus on which an offset-halves journal bearing of 70 $\mathrm{mm}$ diameter journal was tested at five vertical loads and two rotational speeds. Prabhakaran et al. ${ }^{8)}$ have presented the effects of bearing deformation on the static and dynamic performance characteristics of an elliptical bearing. The authors have used finite element method to solve three-dimensional Navier-Stokes, continuity \& elasticity equations, and the characteristics presented by them takes into account the flexibility of the bearing liner. Singh et al. ${ }^{9)}$ have studied the effects of bearing linear elastic deformation and lubricant viscosity with pressure and temperature for an elliptical journal bearing and solved the three-dimensional momentum, continuity and elasticity equations to obtain pressure in the lubricant flow-field and deformation in the bearing liner.
Fitzgerald and $\mathrm{Neal}^{10)}$ presented some experimental data for $76 \mathrm{~mm}$ diameter two-axial groove circular bearings. According to their results, the axial temperature variation was negligible but the circumferential temperature variation could be very significant.

Indulekha et al. ${ }^{11)}$ have solved three dimensional momentum and continuity equations and three dimensional energy equations to obtain pressure, velocity and temperature field in the fluid of a hydrodynamic circular journal bearing using finite element method. Authors have computed the attitude angle, end leakage and the power loss, for a wide range of eccentricity ratios. Hussain et al. ${ }^{12)}$ have predicted the temperature distribution in non-circular journal bearings (namely two-lobe, elliptical, and orthogonally displaced). The prediction of temperature by the authors is based on a two-dimensional treatment following Mc Callion's approach (an approach in which the Reynolds and energy equations in oil film are decoupled by neglecting all pressure terms in the energy equation). Ma and Taylor ${ }^{13)}$ experimentally investigated the thermal behaviour of a two-axial-groove circular bearing and an elliptical (lemon bore) bearing, both $110 \mathrm{~mm}$ in diameter. Both bearings were tested at specific loads upto $4 \mathrm{MPa}$ and rotational frequencies up to $120 \mathrm{~Hz}$. Power losses and flow rate were measured directly and detailed temperature information was collected. The result shows that the thermal effects are significant in both bearings.

Sehgal et al. ${ }^{14)}$ presented a comparative theoretical analysis of three types of hydrodynamic journal bearing configurations namely, circular, axial groove, and offset-halves. It has been observed by the authors that the offset bearing runs cooler than an equivalent circular bearing with axial grooves. Banwait and Chandrawat ${ }^{15}$ analyzed the effect of journal misalignment on the thermohydrodynamic performance characteristics of elliptical journal bearing. The generalized Reynolds equation is solved for the oil-film pressure distribution. The energy and heat conduction equations are used for determining the oil-film, bush and journal temperature fields. The important features observed in static performance characteristics of thermohydrodynamic analysis of misaligned elliptical bearing are reported along with the isopressure curves, pressure profiles, isotherms and temperature profiles. A computer-aided design of hydrodynamic journal bearing is provided considering thermal effects by Singh and Majumdar ${ }^{16)}$. The authors have solved the Reynolds equation simultaneously along with the Energy equation and heat conduction equations in bush and shaft to obtain the steady-state solution. A data bank is generated by the authors that consists of load, friction factor and flow rate for different $L / D \&$ eccentricity ratios.

Mishra et al. ${ }^{17)}$ considered the non-circularity in bearing bore to be elliptical and made a comparison with the circular case to analyse the effect of irregularity. It was observed that with increasing non-circularity the pressure gets reduced and temperature rise is less in case 
of journal bearing with higher non-circularity value. Ostayen and Beek ${ }^{18)}$ have carried out a finite element analysis of a lemon-bore journal bearing. The thermohydrodynamic model presented by the authors is an inverse model, that is, a model in which the shaft eccentricity and attitude angle are calculated given a certain known and prescribed load and load angle. In analysis carried by authors, care has been taken to accurately model the heat to and from the oil supplies and the model is used to check the design of the lemon bearings in a specific naval application.

Hashimoto and Ochiai ${ }^{19)}$ have described that the tilting pad journal bearings are generally used for high-speed rotating machineries because of their advantages of stabilization. However, there are some problems using compact size rotating machineries for their high manufacturing cost and complicated structure. Therefore, authors have proposed a stabilization method of the small-bore journal bearings (circular \& elliptical) based on the combination mechanism with starved lubrication and orientation angle change to enhance the stability compared with tilting pad bearings in order to use for small-size rotating machinery. It has been observed by the authors that the stabilization of small-bore journal bearings is improved drastically by hybrid lubrication combining these two kinds of mechanism.

Chauhan et al. $^{20}$ ) have presented a thermohydrodynamic study for the analysis of elliptical journal bearing with three different grade oils. The authors have made a comparative study of rise in oil-temperatures, thermal pressures, and load carrying capacity for three grade oils. The literature review reveals that almost all the previous experimental work pertains to circular bearings and very little work was concerned with the elliptical journal bearings. In the present work, the thermal effects in an elliptical journal bearing have been studied experimentally using three grade oils namely Oil 1, Oil 2, and Oil 3 at loads varying from $100 \mathrm{~N}$ to $600 \mathrm{~N}$ and speeds $=3000,3500,4000 \mathrm{rpm}$. The experiments were carried out on a specially designed journal bearing setup with provisions of direct flow rate measurement and temperature measurement on three circumferential planes of an elliptical journal bearing machined from Methyl Methacrylite. The experimental setup is described in the next section.

\section{Experimental setup}

The test rig (Fig. 2) has been designed and fabricated under the research grant from MHRD and PDF grant from UGC, New Delhi, India. It is a versatile apparatus, easy to operate with provision to measure temperature on middle and ends (on three circumferential planes) at every 45 degrees angular position on the circumference of bearing, the details of the temperature location is given in Fig. 3. The temperature is measured at 22 different points on the circumference of the bearing using
Resistance temperature detector (RTD). In addition, one sensor is fixed to measure oil inlet temperature. The journal made of $\mathrm{C} 45$ steel material is mounted horizontally on two pedestal bearings. The journal is rotated by a motor through 1:2 ratio pulleys, to attain maximum speed up to $5700 \mathrm{rpm}$. The motor speed is varied by a variable frequency drive; the drive frequency is changed by a potentiometer knob provided on controller front panel. A proximity sensor fixed on the journal, senses its speed. A chrome plated journal sleeve is tightened at middle portion of journal with lock nuts and bearing slides over it. A radial load is applied on bearing by 1:5 loading lever. Smaller end of the lever is hooked to the bearing by link and on bigger end a loading pan is suspended.

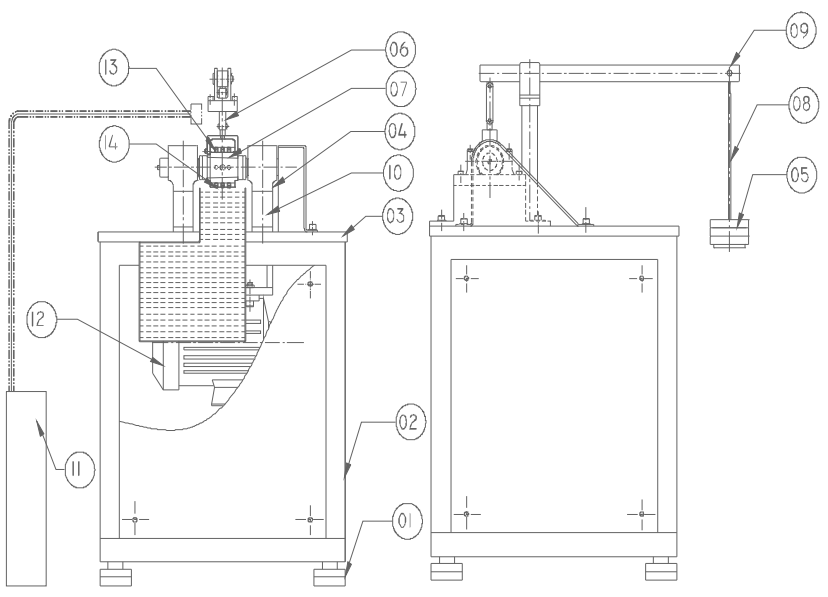

\begin{tabular}{|l|l|l|l|}
\hline Parts & Description & \multicolumn{3}{|l|}{} \\
\hline 01 & Antivibration pad & 08 & Loading pan \\
\hline 02 & Structure & 09 & Lever \\
\hline 03 & Base plate & 10 & Time belt \\
\hline 04 & Plummer block & 11 & Lube system \\
\hline 05 & Dead weight & 12 & Motor \\
\hline 06 & Lifting support lever & 13 & Journal bearing \\
\hline 07 & Sleeve & 14 & Journal bearing \\
\hline
\end{tabular}

Fig. 2 Designed journal bearing test rig

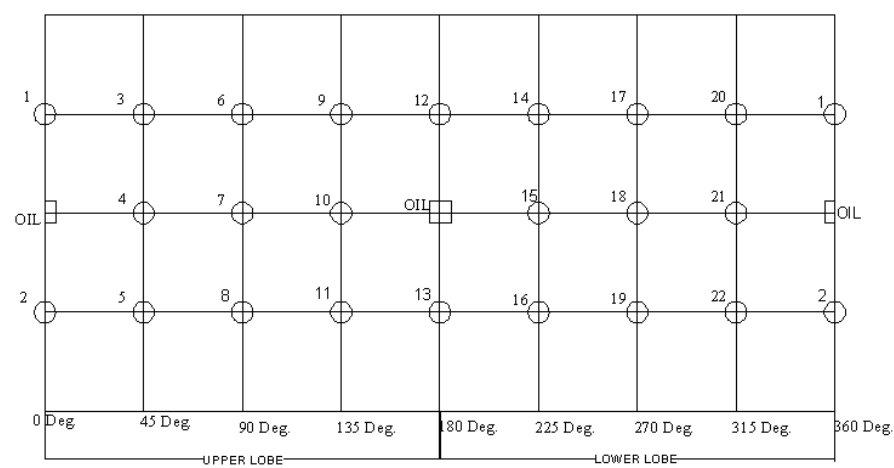

Fig. 3 Locations of RTD sensors for oil film temperature measurement 
The test rig is designed to apply a maximum radial load up to $700 \mathrm{~N}$. An rpm sensor disc with square shape is fixed to journal end and rotates along with it. Proximity sensor is mounted perpendicular to it on bracket fixed to the base plate; signal is generated when senor disc approached the active surface within the specified switching distance. This sensor functions in contact less fashion and do not require any sensing mechanisms. An inductive proximity sensor is used as it has an excellent means of detecting the presence of a wide range of metallic targets. This detection is accomplished without contacting the target and is mechanically wear free. It is comprised of a high frequency oscillator circuit followed by level detector, a post amplification signal circuit and drives a buffered solid-state output. When the sensor disc is brought within the effective range of emitted field of the oscillator, a damping action results, which reduces the amplitude of oscillator. This amplitude shift is converted to digital signal by the level detector, which drives a buffer stage. When the object is removed, the oscillator and digital output is turned to its former state. The controller is housed inside the metal box.

A power ON switch is fixed on front panel for switching ON power supply, a potentiometer knob for regulating speed, push button TEST ON and OFF switch is provided to begin and end the test. On back panel, a $2 \mathrm{~A}$ fuse holder, a 19 pin MS connector for control cables, 25 pin $\mathrm{D}$ connector for signal output 1 and 25 pin $\mathrm{D}$ connector for signal output 2 and 19 pin D connector for signal input. Data acquisition system includes signal output cable 1 and 2, and, WINDUCOM 2005 software. The measured data of oil temperature and speed obtained during the experimentation in analog form is converted into digital form and preprocessed on the instrumentation card. Then this data is serially transmitted to PC through signal output cable 1 and 2 . The data received, displayed and stored on the PC using Lab view based software WINDUCOM 2005. Lubrication unit is made of a metallic tank with a motor \& pump, by pass valve, control valve, pressure gauges, flow meter, inlet and delivery pipe. The discharge of the oil is controlled by means of gate valves provided. Two oil inlets on the bearing are provided with $1 / 2$ " pipe, oil flow is regulated by two gate valves and pressure at that point is indicated by two pressure gauges fixed in line. An oil sump is provided beneath the bearing for collecting the used oil which flows into metallic tank for its re-circulation.

Viscosity of lubricating oil is determined by using FUNGILAB Digital Readout Viscometer Model "VISCOBASIC L". VISCOBASIC L is made to determine viscosity based on the rotational principle that consists of spinning a submerged spindle in the test material at a constant speed and at desired temperature $\left(20-100{ }^{\circ} \mathrm{C}\right)$. The resistance generated by the test material on this spindle is directly proportional to its viscosity. Measuring range of the viscosity of this model is $6 \mathrm{mPas}$ to $2 \times 10^{6} \mathrm{mPas}$.

\section{Experimental programme}

In present experimentation, an elliptical journal bearing (Fig. 4) was tested using three grade oils namely Oil 1, Oil 2, and Oil 3 at loads $=200 \mathrm{~N}, 400 \mathrm{~N}$, and $500 \mathrm{~N}$ and speeds $=3000,3500$, and $4000 \mathrm{rpm}$ at constant pressure $(0.3 \mathrm{MPa})$. The oil was supplied through two oil grooves at $90^{\circ}$ to the vertical loading line. Tests were conducted for various combinations of the operating parameters shown in Table 1.

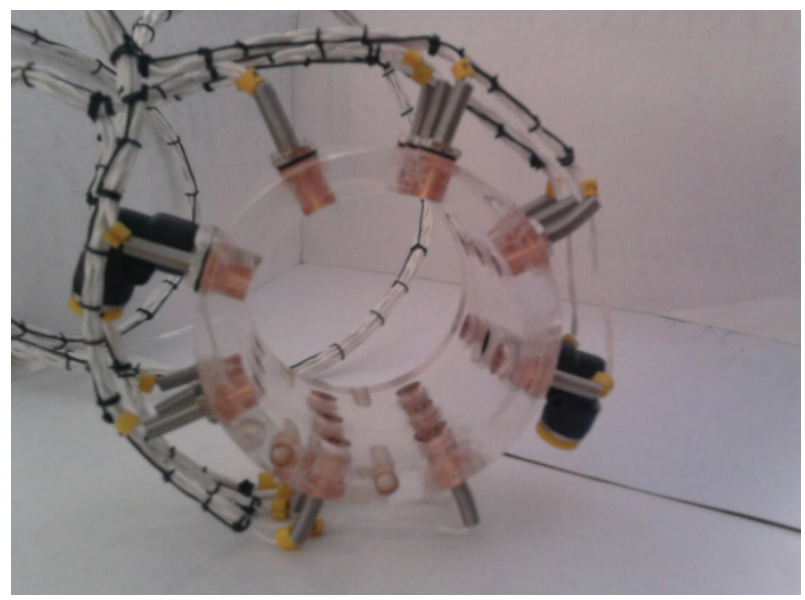

Fig. 4 Designed elliptical journal bearing made of Methyl Methacrylite with RTD Sensors

\section{Results and discussion}

Input parameters and properties of the oils under study are given in Table 2 and Table 3 respectively. Figs. $5(a, b$, and c)-7 (a, b, and c) presents the variation of circumferential temperature at the oil-bush interface on a central plane for a speeds $=3000,3500,4000 \mathrm{rpm}$ respectively, a constant oil pressure $(0.3 \mathrm{MPa})$ and at and c) show the variation of oil temperature across the under consideration. Figures $8(a, b$, and $c)$ to $10(a, b$, journal

Table 1 Test operating conditions

\begin{tabular}{|l|l|}
\hline Outer diameter of the bearing, $O D$ & $85 \mathrm{~mm}$ \\
\hline Maximum inner diameter of the bearing, $D_{\text {Imax }}$ & $65.4 \mathrm{~mm}$ \\
\hline Minimum inner diameter of the bearing, $D_{\text {Imin }}$ & $65.2 \mathrm{~mm}$ \\
\hline Length, $L$ & $65 \mathrm{~mm}$ \\
\hline Radial Clearance, $C$ & $300 \mu \mathrm{m}$ \\
\hline Minimum Clearance, $C_{m}$ & $200 \mu \mathrm{m}$ \\
\hline
\end{tabular}

Table 2 Input parameters

\begin{tabular}{|l|l|}
\hline Oil inlet temperature, $T_{0}$ & $30{ }^{\circ} \mathrm{C}$ \\
\hline Lubricants & Oil 1, Oil 2, and Oil 3 \\
\hline Rotational speeds, $n$ & 3000,3500 , and $4000 \mathrm{rpm}$ \\
\hline Loads, $W$ & 200,400, and $500 \mathrm{~N}$ \\
\hline Oil inlet pressure, $P$ & $0.3 \mathrm{MPa}$ \\
\hline
\end{tabular}


Table 3 Properties of the material and oils under study

\begin{tabular}{|l|c|c|c|}
\hline & Oil 1 & Oil 2 & Oil 3 \\
\hline $\begin{array}{l}\text { Viscosity, } \mu \text { (at oil temperature, } 33 \\
{ }^{\circ} \mathrm{C} \text { ) Pas }\end{array}$ & 0.075 & 0.065 & 0.200 \\
\hline Density, $\rho \mathrm{kg} / \mathrm{m}^{3}$ & 880 & 868 & 885 \\
\hline Thermal Conductivity, Koil W/mK & 0.126 & 0.126 & 0.126 \\
\hline Barus viscosity-pressure index, $\alpha$ & \multicolumn{3}{|c|}{$2.3 \times 10^{-8} \mathrm{~Pa}^{-1}$} \\
\hline Temperature viscosity coefficient, $\gamma$ & \multicolumn{3}{|c|}{$0.034 \mathrm{~K}^{-1}$} \\
\hline $\begin{array}{l}\text { Convection heat transfer coefficient } \\
\text { of bush, } h c\end{array}$ & \multicolumn{3}{|c|}{$100 \mathrm{~W} / \mathrm{mK}$} \\
\hline
\end{tabular}

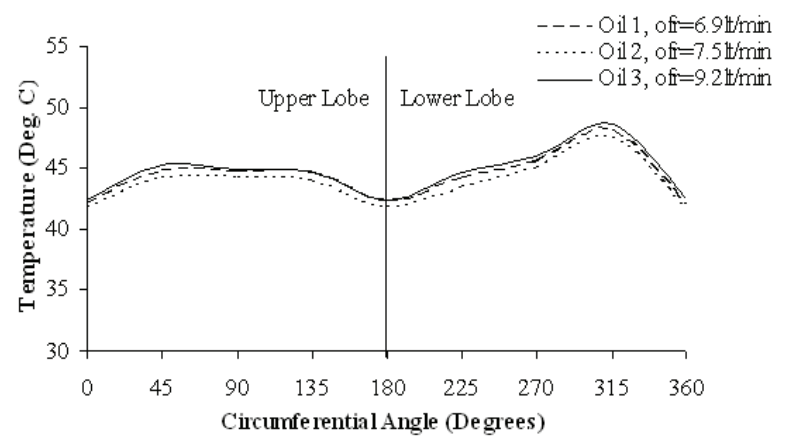

$\mathrm{a}($ Speed $=3000 \mathrm{rpm}, \mathrm{Load}=200 \mathrm{~N}, \&$ Oil inlet Pressure $=0.3 \mathrm{MPa})$

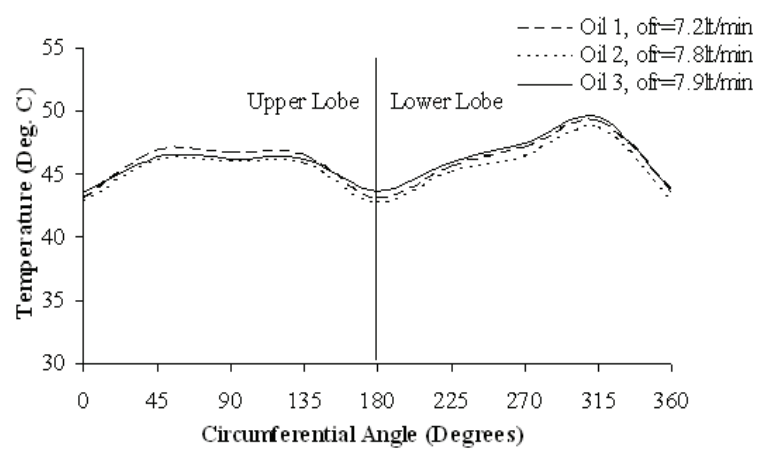

$\mathrm{b}($ Speed $=3000 \mathrm{rpm}, \mathrm{Load}=400 \mathrm{~N}, \&$ Oil inlet Pressure $=0.3 \mathrm{MPa})$

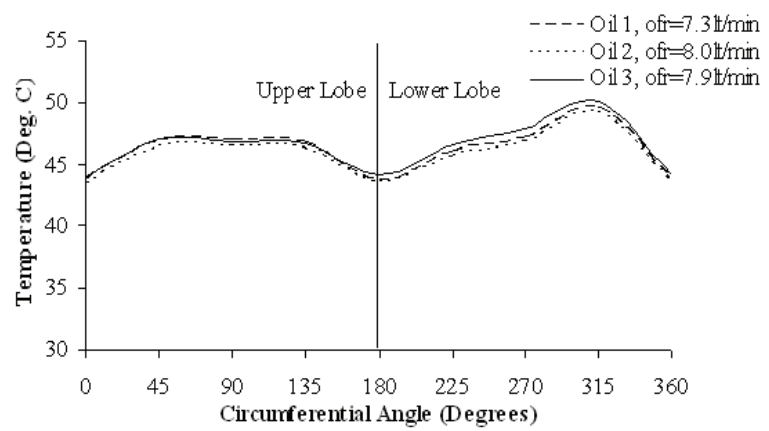

$\mathrm{c}($ Speed $=3000 \mathrm{rpm}, \mathrm{Load}=500 \mathrm{~N}, \&$ Oil inlet Pressure $=0.3 \mathrm{MPa})$

Figs. 5 (a, b, and c) Circumferential variation of oil film temperature in the central plane of elliptical bearing at different operating conditions loads of 200, 400, and $500 \mathrm{~N}$ for all the three grade oils width of the elliptical journal bearing at speed $=4000$ $\mathrm{rpm}$, loads $=200,400,500 \mathrm{~N}$ for all the grade oils under study.

It is observed that:

1. For all the grade oils under study, with increase in the load at same speed and pressure, the temperature of bearing has been found increasing. Also, the temperature of bearing has been observed to be increasing with increase in speed at same load and pressure for the each grade oil. Temperature rise is less at high loads and is nearly equal at high speeds, when compared with

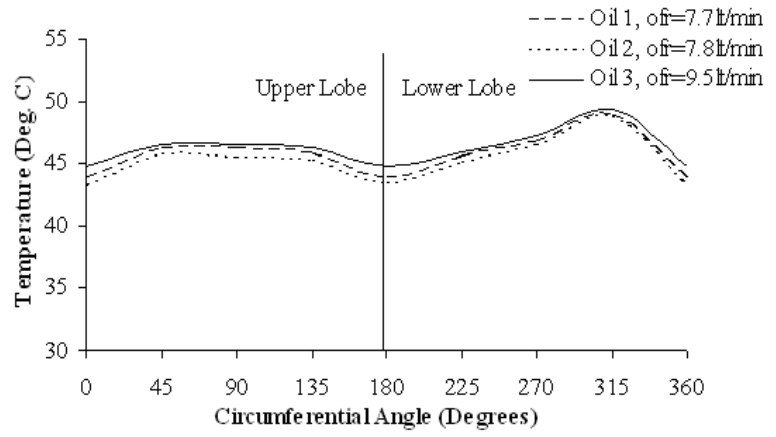

$\mathrm{a}($ Speed $=3500 \mathrm{rpm}, \mathrm{Load}=200 \mathrm{~N}, \&$ Oil inlet Pressure $=0.3 \mathrm{MPa})$

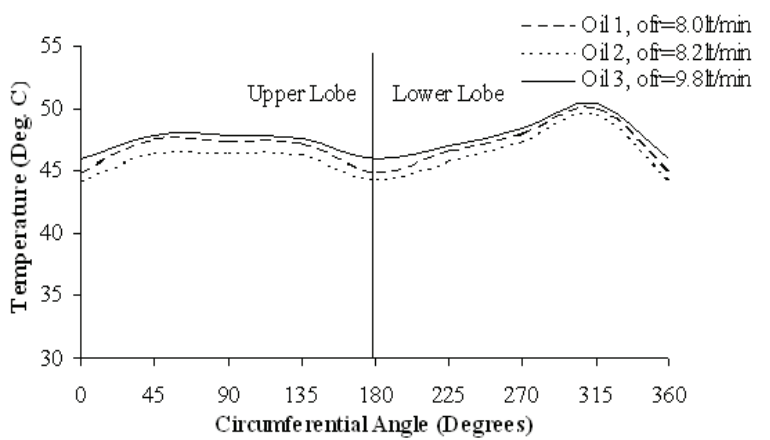

$\mathrm{b}($ Speed $=3500 \mathrm{rpm}, \mathrm{Load}=400 \mathrm{~N}, \&$ Oil inlet Pressure $=0.3 \mathrm{MPa})$

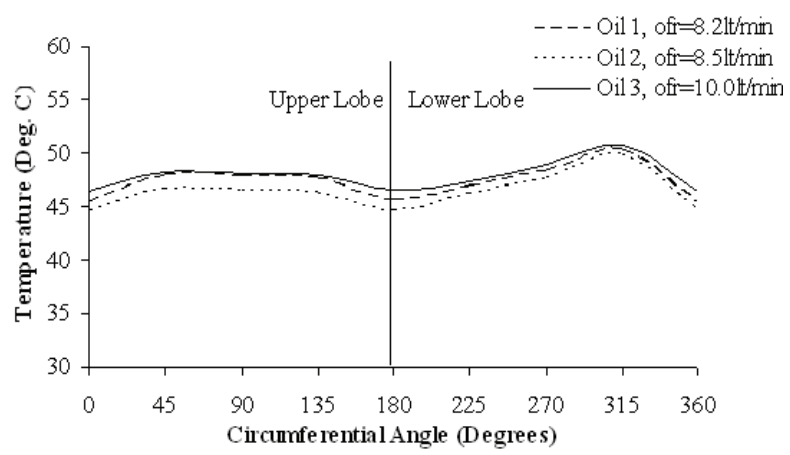

$\mathrm{c}($ Speed $=3500 \mathrm{rpm}, \mathrm{Load}=500 \mathrm{~N}, \&$ Oil inlet Pressure $=0.3 \mathrm{MPa})$

Figs. 6 (a, b, and c) Circumferential variation of oil film temperature in the central plane of elliptical journal bearing at different operating conditions 


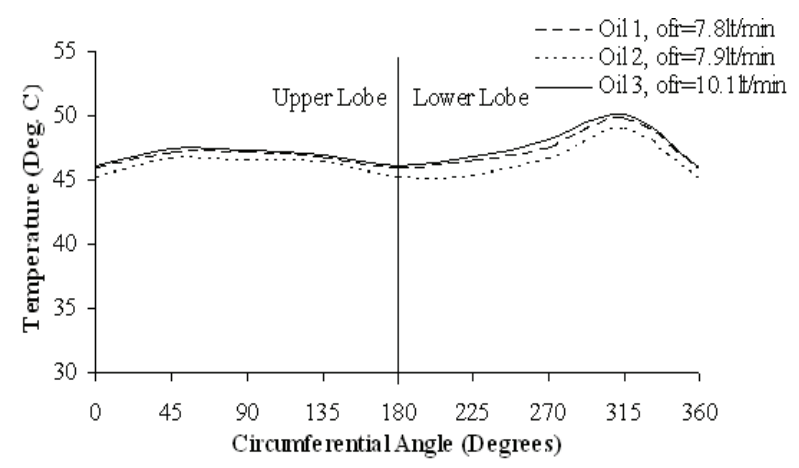

$\mathrm{a}($ Speed $=4000 \mathrm{rpm}, \mathrm{Load}=200 \mathrm{~N}, \&$ Oil inlet Pressure $=0.3 \mathrm{MPa})$

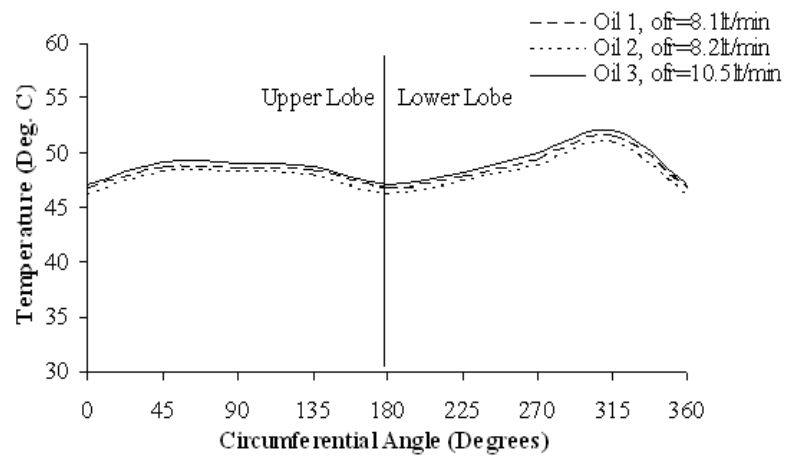

$\mathrm{b}($ Speed $=4000 \mathrm{rpm}, \mathrm{Load}=400 \mathrm{~N}, \&$ Oil inlet Pressure $=0.3 \mathrm{MPa})$

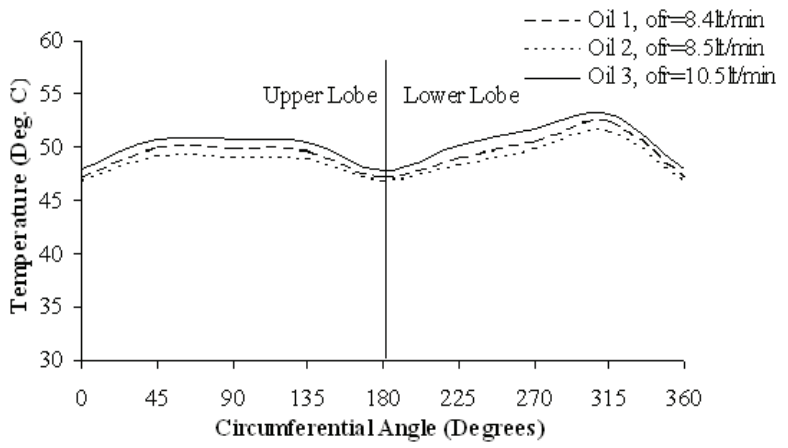

$\mathrm{c}($ Speed $=4000 \mathrm{rpm}, \mathrm{Load}=500 \mathrm{~N}, \&$ Oil inlet Pressure $=0.3 \mathrm{MPa})$

Figs. 7 (a, b, and c) Circumferential variation of oil film temperature in the central plane of elliptical journal bearing at different operating conditions

(which may be because of viscosity variation with increasing temperature) which has been measured directly with the help of a discharge measurement meter fitted to the test rig. The temperature rise is least for Oil 2. For low speeds, temperature rise is higher for Oil 3 at low loads and temperature rise is higher for Oil 1 at high loads. For high speeds, temperature rise is highest for Oil

3. This is probably due to the fact that it is highly viscous in nature which results in high frictional heat generation because of rubbing between oil layers. Owing to the configuration of elliptical bearing, it will have an active oil film in each lobe i.e. lower and upper lobe thus minimizing the cavitation zone (from approx. $180^{\circ}$ in attributed to the more oil being pumped into the system temperature rise at low loads \& speeds. This can be case of circular bearing to approximately $50^{\circ}$ for elliptical

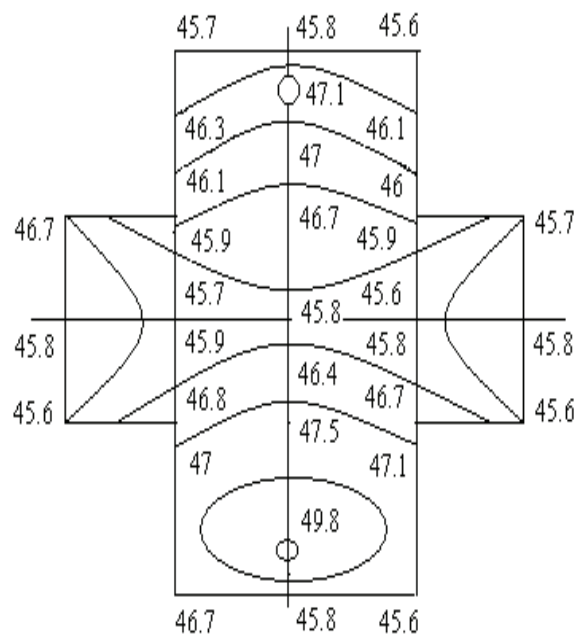

a $($ Speed $=4000 \mathrm{rpm}$, Load $=200 \mathrm{~N}, \&$ Oil inlet Pressure $=0.3 \mathrm{MPa})$

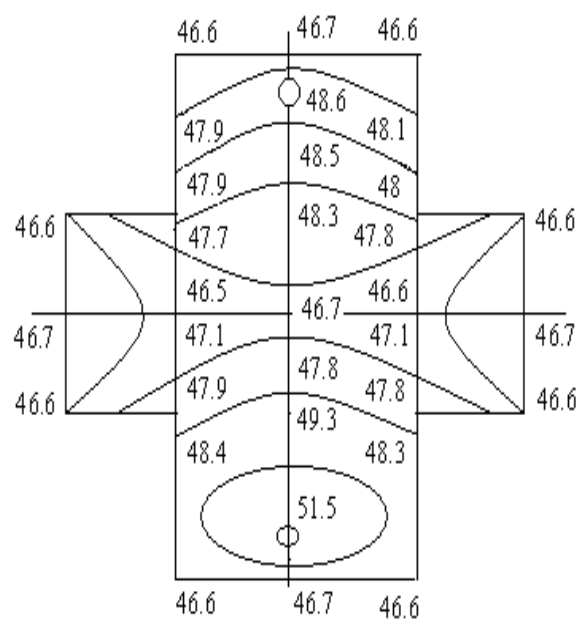

$\mathrm{b}($ Speed $=4000 \mathrm{rpm}, \mathrm{Load}=400 \mathrm{~N}, \&$ Oil inlet Pressure $=0.3 \mathrm{MPa})$

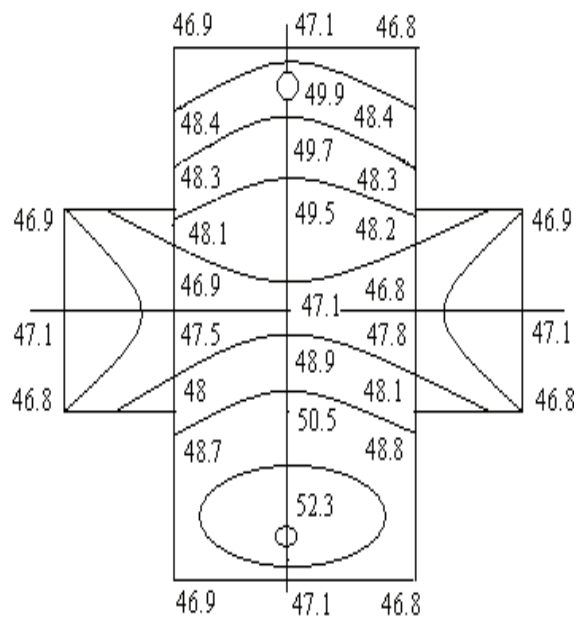

$\mathrm{c}($ Speed $=4000 \mathrm{rpm}, \mathrm{Load}=500 \mathrm{~N}, \&$ Oil inlet Pressure $=0.3 \mathrm{MPa})$

Figs. $8\left(\mathrm{a}, \mathrm{b}\right.$, and c) Temperature distribution $\left({ }^{\circ} \mathrm{C}\right)$ in elliptical journal bearing at different operating conditions for Oil 1 
journal bearing). Hence both the lobes will have converging and diverging oil film zones (Refer Fig. 1) which will lead to rise in oil temperature in both lobes (maximum temperature, being expected near the

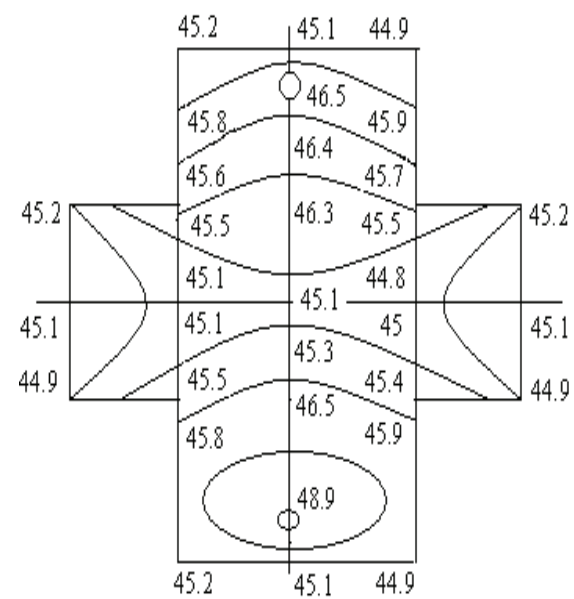

a $($ Speed $=4000 \mathrm{rpm}$, Load $=200 \mathrm{~N}, \&$ Oil inlet Pressure $=0.3 \mathrm{MPa})$

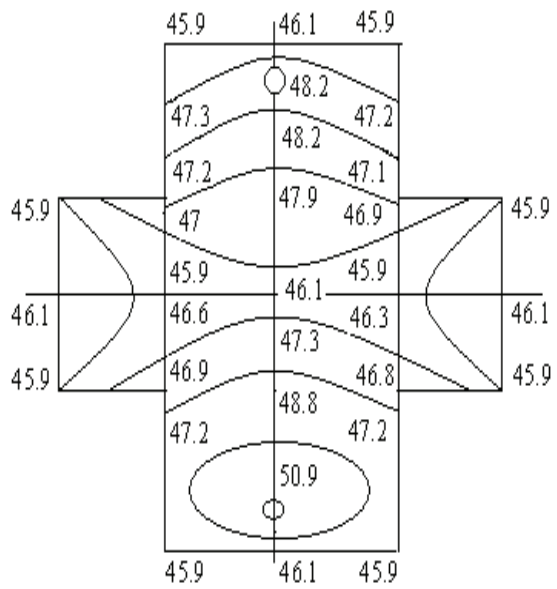

$\mathrm{b}($ Speed $=4000 \mathrm{rpm}, \mathrm{Load}=400 \mathrm{~N}, \&$ Oil inlet Pressure $=0.3 \mathrm{MPa})$

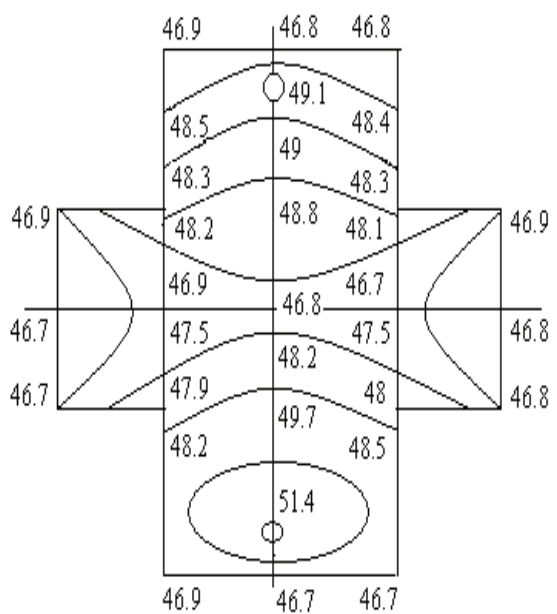

$\mathrm{c}($ Speed $=4000 \mathrm{rpm}, \mathrm{Load}=500 \mathrm{~N}, \&$ Oil inlet Pressure $=0.3 \mathrm{MPa})$

Figs. 9 (a, b, and c) Temperature distribution $\left({ }^{\circ} \mathrm{C}\right)$ in elliptical journal bearing at different operating conditions for Oil 2 minimum film thickness in both the lobes). It has been observed during experimentation that as a result of loading (upward in the lower lobe), the maximum temperature rise is obtained near the point of minimum

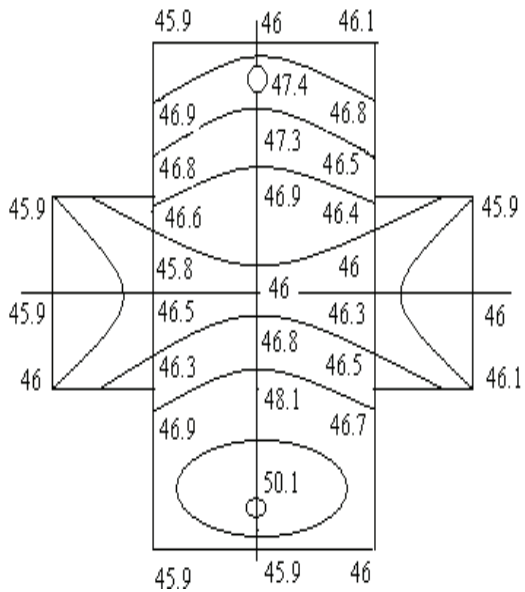

a $($ Speed $=4000 \mathrm{rpm}$, Load $=200 \mathrm{~N}, \&$ Oil inlet Pressure $=0.3 \mathrm{MPa})$

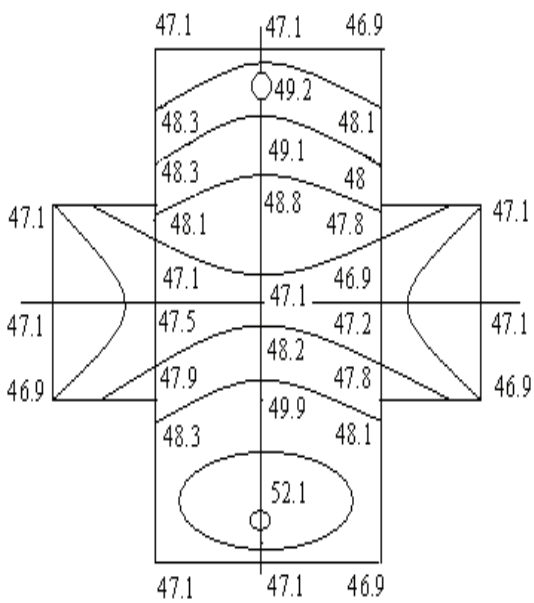

$\mathrm{b}($ Speed $=4000 \mathrm{rpm}$, Load $=400 \mathrm{~N}, \&$ Oil inlet Pressure $=0.3 \mathrm{MPa})$

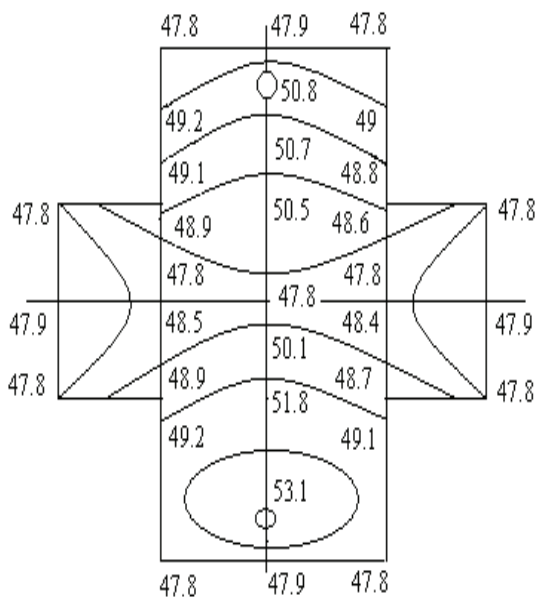

$\mathrm{c}($ Speed $=4000 \mathrm{rpm}, \mathrm{Load}=500 \mathrm{~N}, \&$ Oil inlet Pressure $=0.3 \mathrm{MPa})$

Figs. $10\left(\mathrm{a}, \mathrm{b}\right.$, and c) Temperature distribution $\left({ }^{\circ} \mathrm{C}\right)$ in elliptical journal bearing at different operating conditions for Oil 3 
film thickness in the lower lobe. The oil temperature rise is also obtained near the point of minimum film thickness in the upper lobe, which, however, is $2-3{ }^{\circ} \mathrm{C}$ low in comparison to the oil temperature rise obtained in the lower lobe. For lower lobe, the maximum oil temperature rise is observed as $23.1^{\circ} \mathrm{C}$ for Oil 3 at $4000 \mathrm{rpm}$ and 500 $\mathrm{N}$ and minimum rise is observed as $17.5^{\circ} \mathrm{C}$ for Oil 2 at $3000 \mathrm{rpm}$ and $200 \mathrm{~N}$. For upper lobe, the maximum oil temperature rise is found to be $20.8^{\circ} \mathrm{C}$ for Oil 3 at 4000 rpm and $500 \mathrm{~N}$, and minimum oil temperature rise is found to be $14.1{ }^{\circ} \mathrm{C}$ for Oil 2 at $3000 \mathrm{rpm}$ and $200 \mathrm{~N}$. The oil temperature variations shown in Figs. 5 ( $a, b$, and c) 7 (a, b, and c) start with a higher value of the oil temperature than the oil inlet temperature and this may be because of the effect of the recirculation and hot oil mixing during the experimentation.

2. Across the width of the bearing, oil temperature is high at centre of the bearing for all grade oils and is highest for Oil 3. This is probably due to fact that Oil 3 is highly viscous in nature which results in high frictional heat generation because of the rubbing between oil layers. Maximum oil temperature rise at the centre of the bearing is observed as $17.9{ }^{\circ} \mathrm{C}$ for Oil 3 at $500 \mathrm{~N}$ and $4000 \mathrm{rpm}$.

3. Flow rate is lowest for Oil 1 and maximum for Oil 3. Flow rate is $6.9 \mathrm{lt} / \mathrm{min}$ for Oil 1, $7.5 \mathrm{lt} / \mathrm{min}$ for Oil 2, and $9.2 \mathrm{lt} / \mathrm{min}$ for Oil 3 at $3000 \mathrm{rpm}$ and $200 \mathrm{~N}$, and is 8.4 $\mathrm{lt} / \mathrm{min}$ for Oil 1, $8.5 \mathrm{lt} / \mathrm{min}$ for Oil 2, and $10.5 \mathrm{lt} / \mathrm{min}$ for Oil 3 at $4000 \mathrm{rpm}$ and $500 \mathrm{~N}$. Flow rate for Oil 3 is large at high speeds and loads as its viscosity decreases sharply with temperature in comparison to the other grade oils considered.

4. It has been observed that the trend of oil film temperature distribution along the circumference of bearing is very close to the oil film temperature distribution obtained by the theoretical model developed

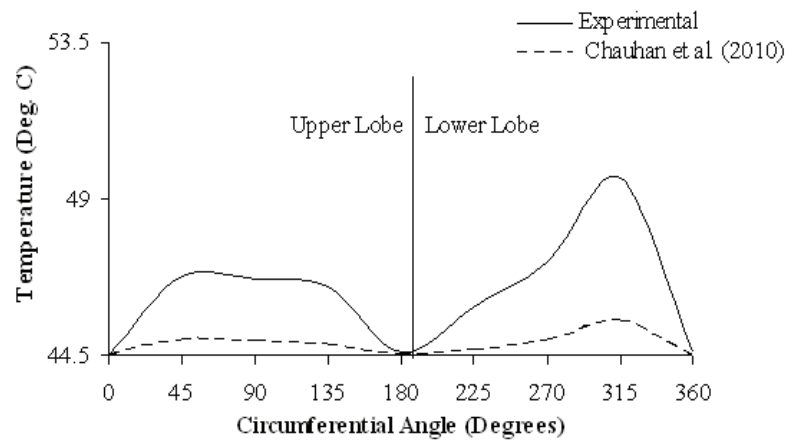

Fig. 11 Comparison of oil film temperature in the central plane of elliptical journal bearing obtained experimentally with the available results of Chauhan et al. (2010) for Oil $2[n=3000 \mathrm{rpm}, \mu$ $=0.038$ Pas, $C=300 \mu \mathrm{m}, L=0.065 \mathrm{~m}, D_{\text {Imin }}=$ $0.0652 \mathrm{~m}, C_{m}=200 \mu \mathrm{m}$, Oil inlet temperature $=$ $\left.44.5{ }^{\circ} \mathrm{C}, \mathrm{Load}=600 \mathrm{~N}\right]$ by Chauhan et al. ${ }^{20)}$ as shown in Fig. 11 for Oil 2. For Fig. 11 , the oil inlet temperature has been taken as $44.5{ }^{\circ} \mathrm{C}$ which is the oil inlet temperature obtained during experimentation at $3000 \mathrm{rpm}$ and $600 \mathrm{~N}$. The oil film temperatures obtained experimentally has been observed to be on higher side than theoretical one, which may be due to the oil recirculation, and mixing of hot oil at the oil inlet.

\section{Conclusion}

An experimental setup/test rig has been developed to investigate the thermal behaviour of non-circular bearings. An elliptical journal bearing was tested and the temperature distributions at the oil bush interface were obtained for a series of operating conditions using three different grade oils. During experimentation the supply pressure parameter was kept constant. From the results and discussion presented in this paper, the following conclusions are drawn: The thermal behaviour of the journal bearing is affected significantly by rotational speed, loads and type of oil used. Flow rate increases markedly with speed and load. For lower lobe, the maximum oil temperature rise is observed as $23.1{ }^{\circ} \mathrm{C}$ for Oil 3 at $4000 \mathrm{rpm}$ and $500 \mathrm{~N}$, and minimum oil temperature rise is observed as $17.5^{\circ} \mathrm{C}$ for Oil 2 at 3000 $\mathrm{rpm}$ and $200 \mathrm{~N}$. For upper lobe, the maximum oil temperature rise is found to be $20.8{ }^{\circ} \mathrm{C}$ for Oil 3 at 4000 $\mathrm{rpm}$ and $500 \mathrm{~N}$, and minimum oil temperature rise is found to be $14.1{ }^{\circ} \mathrm{C}$ for Oil 2 at $3000 \mathrm{rpm}$ and $200 \mathrm{~N}$. Across the width of bearing, oil temperature is highest for Oil 3. Therefore, under the operating conditions, it is more appropriate to use Oil 2 out of the three grade oils considered, as the elliptical journal bearing will run coolest as temperature rise being lowest, thus providing the desired operational accuracies.

\section{Acknowledgement}

The author gratefully acknowledges the financial support provided by MHRD and UGC, New Delhi, India for this work. The author also acknowledges the technical support provided by M/s DUCOM, Bangalore in fabrication of the test rig and bearing profile.

\section{Nomenclature}

\begin{tabular}{|c|c|}
\hline$C$ & Radial clearance, $\mu \mathrm{m}$ \\
\hline$C_{m}$ & $\begin{array}{l}\text { Minimum clearance when journal centre is } \\
\text { coincident with geometric centre of bearing, } \mu \mathrm{m}\end{array}$ \\
\hline$C_{P}$ & Specific heat of lubricating oil, $\mathrm{J} / \mathrm{kgK}$ \\
\hline$D_{\text {Imin }}$ & $\begin{array}{l}\text { Minimum inner diameter of the elliptical journal } \\
\text { bearing, } \mathrm{mm}\end{array}$ \\
\hline$D_{\operatorname{Imax}}$ & $\begin{array}{l}\text { Maximum inner diameter of the elliptical journal } \\
\text { bearing, } \mathrm{mm}\end{array}$ \\
\hline$E$ & Eccentricity, m \\
\hline$h$ & Film thickness for elliptical journal bearing, $\mathrm{m}$ \\
\hline Koil & Thermal conductivityoflubricating oil, W/mK \\
\hline$K s$ & Thermal conductivity of bearing, $\mathrm{W} / \mathrm{mK}$ \\
\hline$L$ & Length of the bearing, $\mathrm{m}$ \\
\hline
\end{tabular}




$\begin{array}{ll}N & \text { Journal Speed, rpm } \\ \text { OD } & \text { Outer diameter of the bearing } \\ \text { ofr } & \text { Oil flow rate, } \mathrm{lt} / \mathrm{min} \\ P & \text { Film Pressure, Pa } \\ R T D & \text { Resistance temperature detector } \\ T_{0} & \text { Oil inlet temperature, }{ }^{\circ} \mathrm{C} \\ W & \text { Load, } \mathrm{N} \\ \theta & \text { Angle measured from the horizontal split axis in the } \\ & \text { direction of rotation } \\ \mu & \text { Absolute viscosity, Pas } \\ \rho & \text { Density of lubricating oil, } \mathrm{kg} / \mathrm{m}^{3} \\ \omega & \text { Angular velocity of shaft, } \mathrm{rad} / \mathrm{s}\end{array}$

\section{References}

[1] Pinkus, O. and Lynn, M., "Analysis of Elliptical Bearings," Trans. ASME, 78, 1956, 965-973.

[2] Suganami, T. and Sezri, A. Z., "A Thermohydrodynamic Analysis of Journal Bearings," Trans. ASME, J. Lub. Techno., 101, 1979, 21-27.

[3] Crosby, W. A., "Thermal Considerations in the Solution of Finite Journal Bearings," Wear, 64, 1980, 15-32.

[4] Singh, A. and Gupta, B. K., "Stability Limits of Elliptical Journal Bearings Supporting Flexible Rotors," Wear, 77, 1982, 159-170.

[5] Tayal, S. P., Sinhasan, R. and Singh, D. V., "Finite Element Analysis of Elliptical Bearings Lubricated by a Non-Newtonian Fluid," Wear, 80, 1982, 71-81.

[6] Boncompain, R. and Fillon, M., Frene, J., "Analysis of Thermal Effects in Hydrodynamic Bearings," Trans. ASME, J. Tribol., 108, 1986, 219-224.

[7] Read, L. J. and Flack, R. D., "Temperature, Pressure and Film Thickness Measurements for an Offset Half Bearing," Wear, 117, 1987, 197-210.

[8] Prabhakaran, N. K., Sinhasan, R. and Singh, D. V., "Elastohydrodynamic Effects in Elliptical Bearing," Wear, 118, 1987, 129-145.

[9] Singh, D. V., Sinhasan, R. and Prabhakaran, N. K., "Elastothermohydrodynamic Effects in Elliptical Bearings," Tribol. Int., 22, 1, 1989, 43-49.
[10] Fitzgerald, M. K. and Neal, P. B., “Temperature Distributions and Heat Transfer in Journal Bearings," Trans. ASME, J. Tribol., 144, 1992, 122-130.

[11] Indulekha, T. P., Joy, M. L. and Prabhakaran, N. K., "Fluid Flow and Thermal Analysis of a Circular Journal Bearing," Warme-und stoffubertragung, 29, 1994, 367-371.

[12] Hussain, A., Mistry, K., Biswas, S. and Athre, K., "Thermal Analysis of Non-Circular Bearing," Trans. ASME, J. Tribol., 118, 1996, 246-254.

[13] Ma, M. T. and Taylor, M., "An Experimental Investigation of Thermal Effects in Circular and Elliptical Plain Journal Bearings," Tribol. Int, 29, 1996, 19-26.

[14] Sehgal, R., Swamy, K. N. S., Athre, K. and Biswas, S., "A Comparative Study of the Thermal Behaviour of Circular and Non-Circular Journal Bearings," Lub. Sci., 12, 2000, 329-344.

[15] Banwait, S. S. and Chandrawat, H. N., "Effect of Misalignment on Thermohydrodynamic Analysis of Elliptical Journal Bearings," Journal of the Institution of Engineers (India): Mechanical Engineering Division, 81, 3, 2000, 93-101.

[16] Singh, D. S. and Majumdar, B. C., "Computer-Aided Design of Hydrodynamic Journal Bearings Considering Thermal Effects," Proc. Inst. Mech. Eng., Part J: J. Eng. Tribol., 219, 2005, 133-143.

[17] Mishra, P. C., Pandey, R. K. and Athre, K., "Temperature Profile of an Elliptic Bore Journal Bearing," Tribol. Int., 40, 2007, 453-458.

[18] Ostayen, R. A. J. V. and Beek, A. V., "Thermal Modelling of the Lemon-Bore Hydrodynamic Bearing," Tribol. Int., 42, 2009, 23-32.

[19] Hashimoto, H. and Ochiai, M., "Experimental Study on the Stabilization of Small-Bore Journal Bearing by Controlling Starved Lubrication and Bearing Orientation Angle," Trans. ASME, J. Tribol., 31, 2009, 011705.

[20] Chauhan, A., Sehgal, R. and Sharma, R. K., "Thermohydrodynamic Analysis of Elliptical Journal Bearing with Different Grade Oils," Tribol. Int., 23, 2010, 1970-1977. 